\title{
Mechanosensitive channels: feeling tension in a world under pressure
}

\author{
Rémi Peyronnet ${ }^{1}$, Daniel Tran $^{2}$, Tiffanie Girault $^{2}$ and Jean-Marie Frachisse ${ }^{2} *$ \\ National Heart and Lung Institute, Imperial College London, London, UK \\ 2 Institut des Sciences du Végétal - Centre National de la Recherche Scientifique, Saclay Plant Sciences, Gif-sur-Yvette, France
}

\section{Edited by:}

Gabriele B. Monshausen,

Pennsylvania State University, USA

\section{Reviewed by:}

Hidetoshi lida, Tokyo Gakugei

University, Japan

Boris Martinac, Victor Chang Cardiac

Research Institute, Australia

\section{${ }^{*}$ Correspondence:}

Jean-Marie Frachisse, Institut des Sciences du Végétal - Centre National de la Recherche Scientifique, Saclay Plant Sciences, Bat 22-23A, Avenue de la Terrasse, 91198 Gif-sur-Yvette, France e-mail: jean-marie.frachisse@isv. cnrs-giffr
Plants, like other organisms, are facing multiple mechanical constraints generated both in their tissues and by the surrounding environments. They need to sense and adapt to these forces throughout their lifetimes. To do so, different mechanisms devoted to force transduction have emerged. Here we focus on fascinating proteins: the mechanosensitive (MS) channels. Mechanosensing in plants has been described for centuries but the molecular identification of MS channels occurred only recently. This review is aimed at plant biologists and plant biomechanists who want to be introduced to MS channel identity, how they work and what they might do in planta? In this review, electrophysiological properties, regulations, and functions of well-characterized MS channels belonging to bacteria and animals are compared with those of plants. Common and specific properties are discussed. We deduce which tools and concepts from animal and bacterial fields could be helpful for improving our understanding of plant mechanotransduction. MS channels embedded in their plasma membrane are sandwiched between the cell wall and the cytoskeleton. The consequences of this peculiar situation are analyzed and discussed. We also stress how important it is to probe mechanical forces at cellular and subcellular levels in planta in order to reveal the intimate relationship linking the membrane with MS channel activity. Finally we will propose new tracks to help to reveal their physiological functions at tissue and plant levels.

Keywords: stretch-activated channels, mechanotransduction, mechanobiology, cytoskeleton, plant, MSL, MscS, membrane tension

\section{INTRODUCTION}

All organisms, from bacteria to mammals and plants, experience mechanical forces. These forces are ubiquitous and very diverse coming from both the internal and the external environment. One of the most common external sources of stimulation sensed by both plants and animals is touch (pressure, shear stress). Like animals, plants are sensitive to gravity which guides their growth with respect to the gravity vector. Cells also generate their own intracellular forces as is obvious during cell division, cell elongation, or adjustment after osmotic challenge. While animals have to deal with circulating liquids (blood and urinary) and gases (lungs) as well as contractile elements (muscles), plant cells with their high turgor pressure represent very peculiar and interesting living systems from a mechanical point of view.

Over the last few years, it has become apparent that the ability of cells to sense and adapt to these forces is crucial for a wide range of biological processes. After two decades, during which the vast majority of studies were devoted to the dissection of gene regulatory pathways, mechanics is now being progressively integrated into the network, both as output (the impact of genes on cell mechanics) and input (the impact of mechanical signals on gene activity; Figure 1). Emerging techniques and tools now enable the measurement and manipulation of mechanical forces in vitro and progressively in vivo. This has led to an ongoing renaissance in studying mechanics.
Cells not only survive mechanical stimulation but also use it as a driving force to design their own architecture and to serve biological functions. This explains why cells and organisms have established mechanosensors. Three groups of proteins can fulfill this function: linkage proteins, structural elements, and MS ion channels.

Amongst the most well-known linkage proteins are integrins. These proteins are embedded in the plasma membrane and allow a mechanical coupling between the extra cellular matrix and the actin cytoskeleton. They are well described in the animal field and integrin-like proteins are reported in plants. NDR1 (Non-racespecific Disease Resistance1) for example is suggested to play a role in plasma membrane-cell wall adhesion and is required during plant-pathogen interaction (Knepper et al., 2011). In plants, serine-threonine protein kinases associated with the cell wall are good candidates to transduce mechanical forces. Among them are WAKs and THESEUS receptor-like kinase (RLKs; Monshausen and Gilroy, 2009) and other members of the large family of membrane-localized RLKs (Monshausen and Haswell, 2013). The cytoskeleton can be involved in several steps during mechanotransduction processes as demonstrated extensively in the animal field. It can directly transmit mechanical forces across the cell (Hayakawa et al., 2012) and also greatly control membrane tension (Gauthier et al., 2012) and organization (Jaqaman and Grinstein, 2012). 


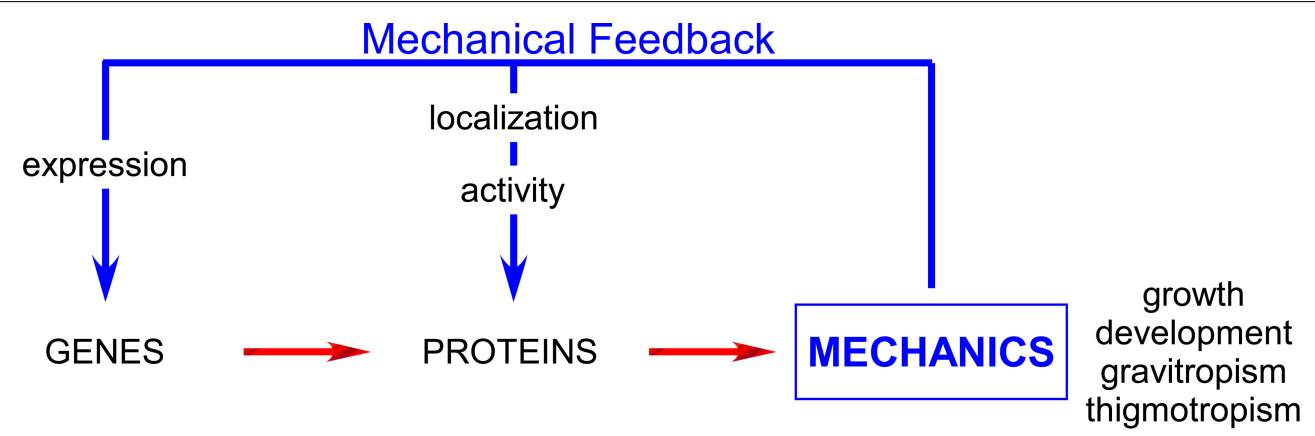

FIGURE 1 | Mechanical feedback affects the whole plant physiology acting on both gene and proteins and plays major role especially in development, growth and tropisms.

In this review we will focus on the most well-known mechanosensors: the MS channels.

\section{MS CHANNELS: A COMMON FEATURE OF LIVING ORGANISMS FROM BACTERIA TO MAMMALS}

Mechanosensitive channels are fascinating proteins, being able to serve both as sensors and effectors. Embedded in membranes, they convert mechanical stimuli such as in-plane membrane tension and curvature into electrical or biochemical signals, leading to regulation of a wide repertoire of cellular processes allowing adaptive response. Directly gated by the mechanical stimulus, MS channels convert (within milliseconds) a mechanical force into electrical trans-membrane potential variation. Therefore MS channels are (with phototransduction) the most rapid transducers known to date in biological systems.

Mechanosensitive channels were discovered in embryonic chick skeletal myocytes by Guharay and Sachs (1984) using the patchclamp technique (Hamill et al., 1981). Then, in 1987 the first recordings were obtained on bacteria (Martinac etal., 1987) and were followed one year later by the first recordings on plants (Falke etal., 1988). It was at this time that the hunt for molecular candidates began. The first MS channel to be cloned was the MscL (MS channel Large conductance) from Escherichia coli in 1994 (Sukharev etal., 1994b) and a second important step was the cloning of the first mammalian MS channel in 1998 (Patel et al., 1998). Since then, deciphering organism genomes has provided several protein candidates for mechanosensing. Numerous other MS channels have been identified but it is only recently (20 years after the first recording of a plant MS channel) that MS channels belonging to two different families were identified in plants (Nakagawa et al., 2007; Haswell et al., 2008). Mid1-Complementing Activity (MCA) exhibiting 10\% identity to yeast Mid1 (Nakagawa et al., 2007) and correlated to $\mathrm{Ca}^{2+}$ influx for MCA1 together with MSL (MscS-Like), homologs of the weakly selective bacterial stretch-activated $\mathrm{MscS}$ channels, have opened a new field of investigation.

The combination of genomics, molecular, and electrophysiological approaches is starting to provide exciting information on the role of MS channels from mechanical perception to organism behavior.
In this review, rather than listing channel candidates characterized within several organisms, we will present some emblematic channels in bacterial and plant systems. We chose to present only well-electrophysiologically characterized channels whose membrane stretching represents a major regulation factor. Exhaustive overviews of the different MS channels characterized can be found notably in (Arnadottir and Chalfie, 2010; Martinac, 2011; Nilius and Honore, 2012; Kurusu et al., 2013; Monshausen and Haswell, 2013; Wilson et al., 2013).

\section{MscL AND MscS: THE BACTERIAL SAFETY-VALVES}

Mechanical senses originated in unicellular organisms. In evolution, the first to appear was osmosensing, which allows a cell to maintain membrane integrity when confronted with varying aqueous environments. In fact, the most extensively characterized MS channels are the MscL (MS channel Large conductance) and MscS (Small conductance; Sukharev et al., 1994a; Levina et al., 1999) which were discovered 25 years ago in bacteria E. coli (Martinac et al., 1987) then cloned in 1994 and 1999 (Sukharev et al., 1994b; Levina et al., 1999) and crystallized in 1998 and 2002 (Chang et al., 1998; Bass et al., 2002). Both have very large conductances, or pore sizes, relative to eukaryotic channels, which are usually on the order of a few 10s of picosiemens; MscL, at about three nanosiemens, meaning a flux of 3 billion ions per second (at a membrane potential of $150 \mathrm{mV}$ ) is the largest gated channel, while MscS conductance is about one nanosiemens (Table 1). These two channels reflect distinct families of proteins. The MscS family, found in several species belonging to bacteria, archaea, algae, fungi, and plants, is quite diverse and a single organism may encode multiple members in its genome. For example, the genome of the model plant Arabidopsis encodes for 10 MscS-like (Haswell and Meyerowitz, 2006). The MscL channel is highly conserved, with only a single copy of the gene found in fungal and bacterial organisms. Unlike most of channels, Msc S and $\mathrm{L}$ have a lack of ionic specificity and are permeable to any charged molecule smaller than 1,000 molecular weight including proline, potassium glutamate, trehalose, and ATP (Hamill and Martinac, 2001). In respect to small ions, MscL is nonselective for both anions and cations (Martinac et al., 2008), whereas MscS exhibits a slight preference for chloride over potassium with a permeability ratio $P C l: P K$ in the range of $1.5-3$ 
Table 1 | Characteristics and functions of the four MS channels, MscL, MscS, TREK-1, and Piezo involved in mechanosensation in bacteria and mammals.

\begin{tabular}{|c|c|c|c|c|}
\hline Channel & MscL & MscS & TREK-1 & Piezo \\
\hline Cloned from (organism) & E. coli & E. coli & Mouse & Mouse \\
\hline $\begin{array}{l}\text { Homologs in other } \\
\text { organisms }\end{array}$ & $\begin{array}{c}\text { Bacteria, archeabacteria, } \\
\text { fungi }\end{array}$ & $\begin{array}{l}\text { Bacteria, algae, fungi, } \\
\text { archaebacteria, plant }\end{array}$ & Mammals & $\begin{array}{c}\text { Mammals, plant, protozoa, } \\
\text { invertebrates }\end{array}$ \\
\hline Conductance & $\sim 3000 \mathrm{pS}[\mathrm{a}, \mathrm{b}]$ & $\sim 1000 \mathrm{pS}[\mathrm{a}, \mathrm{b}]$ & $\sim 50 \mathrm{pS}[\mathrm{c}]$ & $\sim 25-70 \mathrm{pS}[\mathrm{d}, \mathrm{n}, \mathrm{k}]$ \\
\hline Selectivity & not-selective $[b, e]$ & $\begin{array}{c}\text { weak: } \mathrm{Cl}^{-}>\mathrm{K}^{+}>\text {metabolites } \\
{[\mathrm{b}, \mathrm{e}]}\end{array}$ & $\mathrm{K}^{+}[\mathrm{c}]$ & cation non-selective $[d][f]$ \\
\hline Activation & $\mathrm{T}_{1 / 2}: \sim 12 \mathrm{mN} \cdot \mathrm{m}^{-1}[\mathrm{~g}]$ & $\mathrm{T}_{1 / 2}: \sim 6 \mathrm{mN} \cdot \mathrm{m}^{-1}[\mathrm{~h}]$ & $\begin{array}{c}P_{1 / 2}:-20 \text { to }-60 \mathrm{~mm} \mathrm{Hg} \\
{[\mathrm{c}, \mathrm{i}, \mathrm{j}]}\end{array}$ & $\begin{array}{c}P_{1 / 2}:-25 \text { to }-48 \mathrm{~mm} \mathrm{Hg} \\
{[d, k, l]}\end{array}$ \\
\hline Inactivation & No & $\begin{array}{c}\text { Yes (spheroplast) } \\
{[\mathrm{a}, \mathrm{m}]}\end{array}$ & Yes, $\tau \sim 46 \mathrm{~ms}[\mathrm{c}]$ & Yes, $\tau \sim 45 \mathrm{~ms}[\mathrm{n}]$ \\
\hline Functions & "Emergency release valve" & $\begin{array}{l}\text { "Non-emergency release } \\
\quad \text { valve" } \\
\text { Internal crowding sensor }\end{array}$ & $\begin{array}{c}\text { Pain perception, ischemia, } \\
\text { vasodilatation... }\end{array}$ & $\begin{array}{l}\text { Red blood cell volume touch } \\
\text { and pain perception }\end{array}$ \\
\hline
\end{tabular}

a: Perozo and Rees (2003), b: Sukharev etal. (1997), c: Honore etal. (2006), d: Coste etal. (2010):, e: Martinac etal. (2008), f: Bae etal. (2013), g: Sukharev (1999), h: Sukharev (2002), i: Patel etal. (1998), j: Bang etal. (2000), k: Bae etal. (2011), I: Peyronnet etal. (2012), m: Sotomayor etal. (2007), n: Gottlieb etal. (2012), o: Mukherjee etal. (2014), p: Vasquez etal. (2008), q: Maingret etal. (2000).

(Martinac et al., 2008). Each Msc (S or L) in E. coli exhibits a unique threshold tension for activation of $\sim 6.0$ and $\sim 12.0 \mathrm{mN} / \mathrm{m}$ respectively, (Sukharev et al., 1999; Sukharev, 2002; Nomura et al., 2012). Biophysical approaches on MscS and MscL as well as studies performed on purified MscL, show that the protein alone reconstituted into liposomes retained mechanosensitivity, indicating that both channels directly sense membrane tension developed in the lipid bilayer alone (Sukharev et al., 2001; Perozo et al., 2002).

Bacteria are well documented for their ability to survive and grow in conditions of changing osmolarity. When they face a sudden hypoosmotic shock (which may take place, for instance, in gastrointestinal bacteria exposed to food processing, marine bacteria suddenly exposed to fresh water or soil bacteria trapped in rain water), a rapid influx of water will occur. Consequently, the mechanical membrane tension will rapidly rise. This should not exceed around 15 mN.m ${ }^{-1}$ (Evans and Ludwig, 2000; Boer et al., 2011). Above this level the rupture of the membrane will produce lysis of the cell. In order to avoid this situation, excessive membrane tension should be rapidly relieved. Based on experiments performed on knock-out $(\mathrm{KO})$ bacteria, it was proposed by Levina et al. (Levina et al., 1999) that MscS and MscL represent two efficient "valves" acting synergistically allowing osmolyte efflux after swelling. MscS is the non-emergency "valve" while MscL represents the ultimate "valve" before membrane rupture.

Combining electrophysiological analyses of EcMscS mutants with modeling, Rowe etal. (2014) provided an exciting new perspective on $\mathrm{MscS}$ function. The authors addressed the question of macromolecular crowding (Ellis, 2001), which reduces the intracellular volume of solvent available for other molecules, upon MscS functioning. They show that besides its role as an efflux valve, MscS is also one of the sensors of internal crowding of large-molecular-weight compounds. They argue for a function of $\mathrm{MscS}$ in turgid walled-cells on the maintenance of their volume, shape, and mechanical strength by avoiding excessive draining. Considering the thinness of the cytosol compartment (2-10\% of the plant cell volume), which is probably highly crowded, this provides an interesting new function to look for in the MscS-like channels of plant plasma membranes.

\section{TREK-1: A POLYMODAL CHANNEL}

Mechanosensitive channels can be modulated by numerous stimuli other than mechanical ones and TREK channels which are well described in mammals constitute a good example. TREK means TWIK-related potassium channel, TWIK standing for "Tandem of two-pore $\mathrm{K}^{+}$domains in a weak inwardly rectifying $\mathrm{K}^{+}$." In mammals, TREK belongs to the two-pore domain potassium channel $\left(\mathrm{K}_{2 \mathrm{p}}\right)$ family and, as a potassium channel, is responsible for cell repolarization, thus controlling both the resting and the dynamic electrical activity of cells. TREK-1, TREK-2, and TRAAK are the only members being mechanogated and TRAAK is the only eukaryotic MS channel for which crystal structures have been determined (Brohawn etal., 2012, 2013), with the bacterial MscS and MscL being the only other MS channels crystallized so far. TREK-1 together with TRAAK, as bacterial MS channels, retain their mechanosensitivity when reconstituted into 
liposomes (Brohawn et al., 2014) indicating that they are sensitive to stretch without the need for a second messenger or any form of tethering from the cytoskeleton or the extracellular matrix. This common behavior of MscL, MscS, TREK-1, TRAAK shows that the force from lipid (FFL) principle, first proposed for $E$. coli MS channels of spheroplast by Martinac et al. (1987), can be generalized to structurally unrelated eukaryotic channels. The FFL is a fundamental physicochemical principle based on the fact that the self-assembled bilayer necessitates inherent forces that are large and anisotropic. Then, proteins embedded in the bilayer are subjected to these push and pull forces. The principle of FFL and its relevance to MS channels in biophysical and physiological contexts was recently illustrated by Teng et al. (2014).

Several structure function studies also provided crucial information for a better understanding of the gating of these channels and together these approaches contribute to make TREK, one of the most studied MS channels with the bacterial MscS and MscL. Apart from the bilayer itself, TREK-1 activity is regulated by a plethora of stimuli (Table 1). Its activity is up-modulated by heat, intracellular acidosis, depolarization, volatile anesthetics and down-modulated by extracellular activation of PKA and PKC phosphorylation pathways. In addition, stimulation of Gq-coupled receptors, including metabotropic mGluR1, and mGluR5 receptors, inhibits TREK-1 activity (see Dedman et al., 2009; Noel etal., 2011 for review). More directly related to mechanical stimulation, TREK-1 is modulated by heat, lipids (lysophospholipids and polyunsaturated fatty acids) and also by the cytoskeleton acting as a tonic repressor (Lauritzen et al., 2005; Peyronnet et al., 2012). Aside from these regulations, TREK channels are characterized by the existence of several variants produced by alternative splicing and alternative translation initiation also contributing to the diversity of TREK functions. To date, no TREK analog has been found in sequenced plant genomes.

In mammals (humans/mice) TREK-1 has a wide tissue distribution and with its complex gating regulation is involved in diverse biological processes. It plays a central role in ischaemic and epileptic neuroprotection, vasodilatation, depression (Heurteaux et al., 2006), general anesthesia (Heurteaux et al., 2004) and pain perception (Alloui et al., 2006).

\section{PIEZO: A LARGE CHANNEL WITH A ROLE IN MECHANOPERCEPTION}

Piezo protein (from the Greek "píesi” meaning pressure) discovered by Coste etal. (2010) was shown to be an essential component of a cationic non-selective MS channel from mouse neuroblastoma cells (Table 1). The protein is approximately 2500 amino acids long with 24-36 predicted trans-membrane domains showing no homology to other already known MS or voltage sensitive channels. In the membrane, Piezol proteins are found to be organized in a gigantic homotetrameric structure but the experiment did not show that the pore-forming unit was a tetramer.

Coste et al. also cloned a homologous gene called Piezo2 from mouse dorsal root ganglion cells with similar electrophysiological properties. After expression, purification, and reconstitution in artificial lipid bilayers, Piezol was shown to be the pore-forming subunit (Coste et al., 2012). Piezol mutations were associated with autosomal dominant hemolytic anemia (Zarychanski et al., 2012). Patapoutian's group also demonstrated that Piezo2 is expressed in a mechanoreceptor complex in mouse skin and is required for gentle touch perception (Woo et al., 2014). In the same way, Piezo proteins in Drosophila larvae have been shown to be crucial for responses to noxious mechanical stimuli (Coste et al., 2012).

Piezos are fascinating proteins (see Gottlieb and Sachs, 2012; Nilius and Honore, 2012 for reviews) and it is still unclear why these proteins are so big. It is tempting to hypothesize that the large number of transmembrane domains along with the proteins' large size could constitute an effective sensor for membrane curvature. In any case, this unusual structure for a mechanotransducer is likely to suggest other functions. Piezo, an evolutionarily conserved protein, presents a single homolog in the genome of the model plant Arabidopsis, providing an interesting new candidate for plant mechanosensors.

\section{ACCESSING MS ACTIVITY AT CELLULAR LEVEL PATCH-CLAMP COMBINED WITH HIGH SPEED PRESSURE-CLAMP REVEALS INTIMATE PROPERTIES OF MECHANOSENSITIVE CHANNELS}

Patch clamp is a powerful technique that allows the recording of channel activity with a high resolution in terms of time (ms) as well as ion flux (pA). Figure $\mathbf{2 A}$ is a summary of the different configurations that can be achieved in patch clamp. The use of whole cell configuration allows the recording of channel population activity present on a membrane while the other possible patch configurations select a small number of channels at the tip of the pipette, enabling resolution of single channel activity. These latter configurations are reached through a cell attached configuration that maintains intracellular integrity, thus complying with the transduction pathways, or through an excised patch allowing a better characterization through which the ionic environment on both sides of the membrane is fully controlled. Excised patch configurations also allow us to test the role of the cytoskeleton. It has been shown that cytoskeleton elements are strongly destabilized in this configuration in comparison with cell attached mode (Lauritzen et al., 2005; Peyronnet et al., 2012). Only excised and cell attached patches allow application of a large range of pressures and therefore, the highlighting of the relationship between open probability and membrane tension of a single channel. The development of the pressure clamp system in the nineties (McBride and Hamill, 1992; Hurwitz and Segal, 2001) has become a key tool for applying fast pressure steps to membrane patches (Figure 2B). The ability to measure channel relaxations following step changes in positive/negative pressure in combination with patch clamp techniques has launched many studies on the analysis of the time, voltage and pressure dependence of the opening and closing of MS channels from different organisms, exemplified in Figure 2B with the Arabidopsis mechanosensitve MSL10 channel. Thus the relationship between open probability/pressure fits a sigmoid curve called a Boltzmann function, indicating the threshold and maximum (saturation) tension values of the channel. The slope of the sigmoid depicts the strength of the channel dependence toward membrane tension. The most artificial, but best controlled situation, is encountered when the 


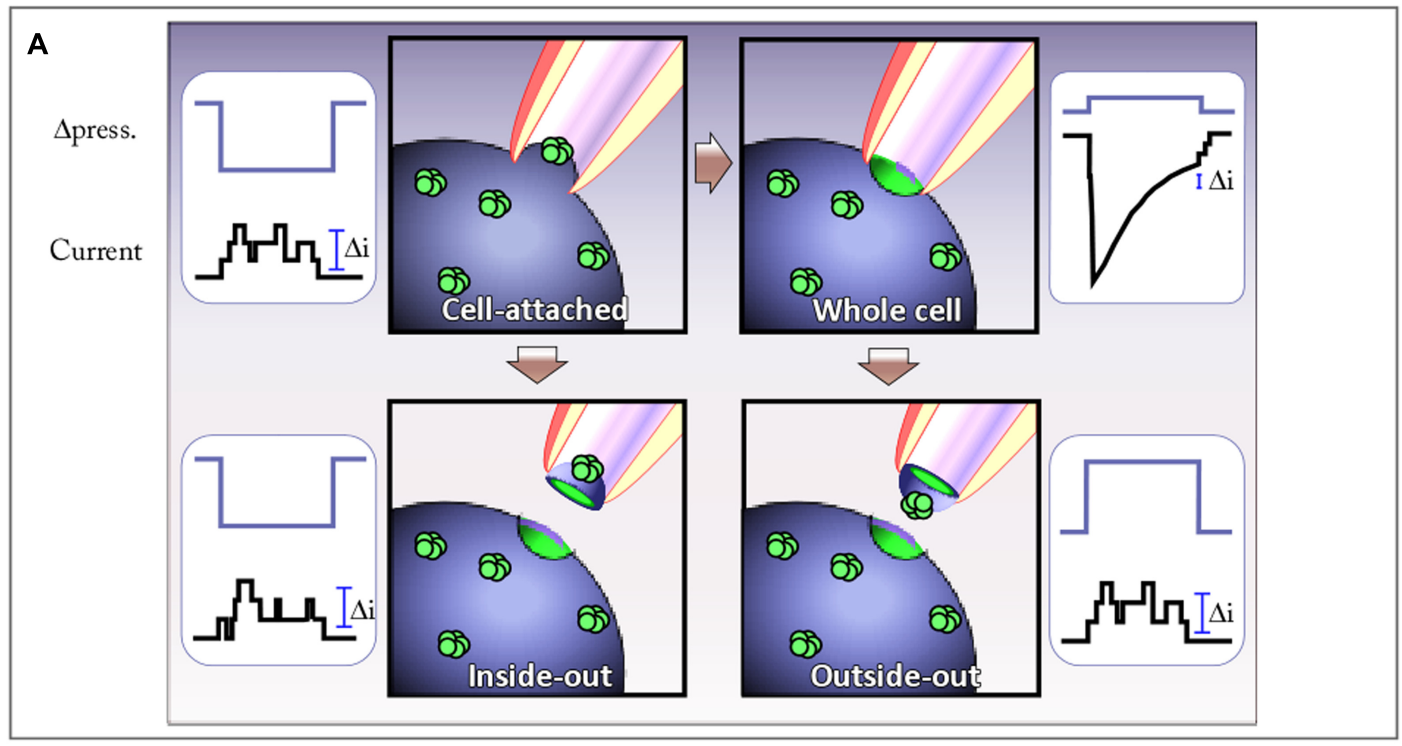

B

MSL 10 protein

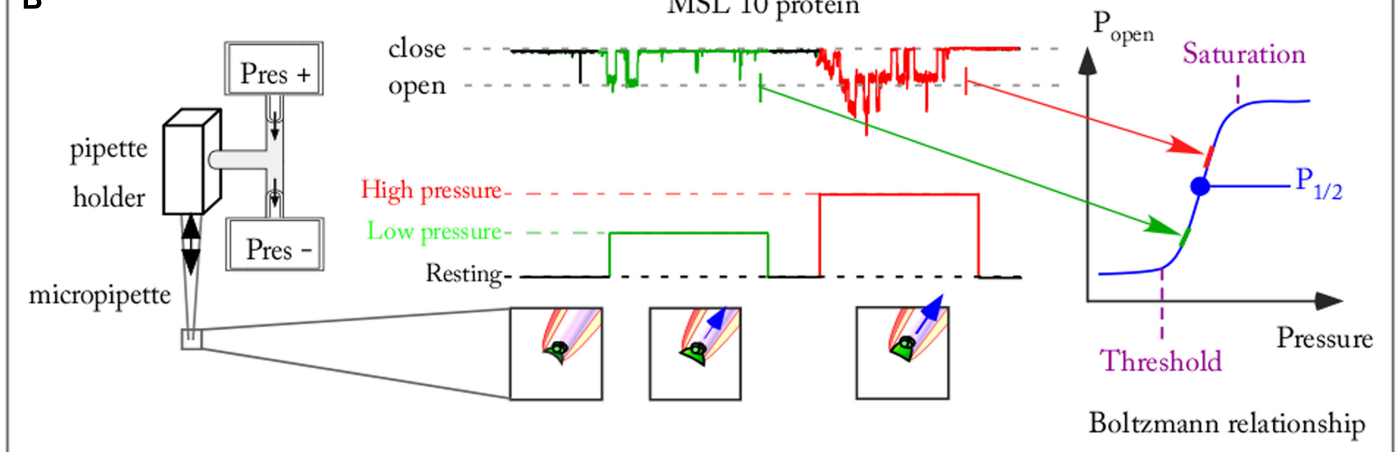

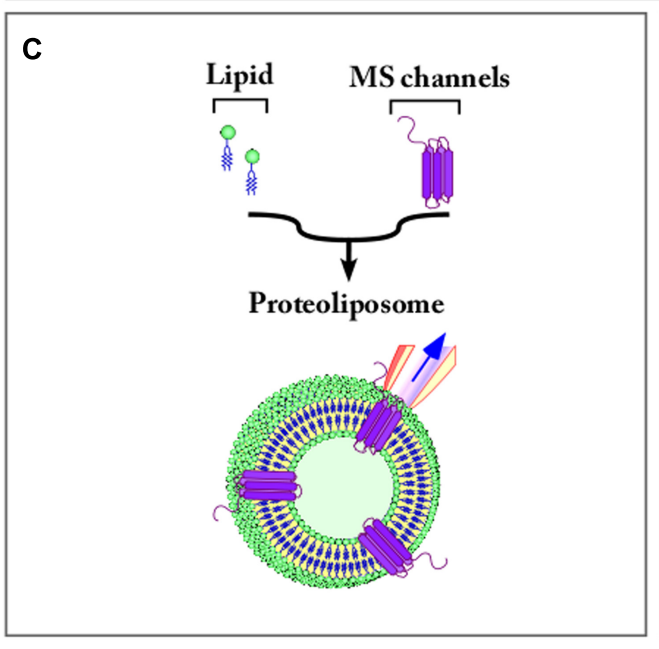

FIGURE 2 | Patch clamp combined with fast speed pressure stimulation allows to study kinetic properties of mechanosensitive (MS) channels. (A) The four patch clamp configuration allowing to record either single channel current (Cell attached, Inside-out, and Outside-out) or a population channel current (Whole cell) are represented. Channels are stimulated by applying a pulse of pressure against the membrane. (B) Recording of the Arabidopsis MSL10 channel activity in outside-out configuration. The activity of the

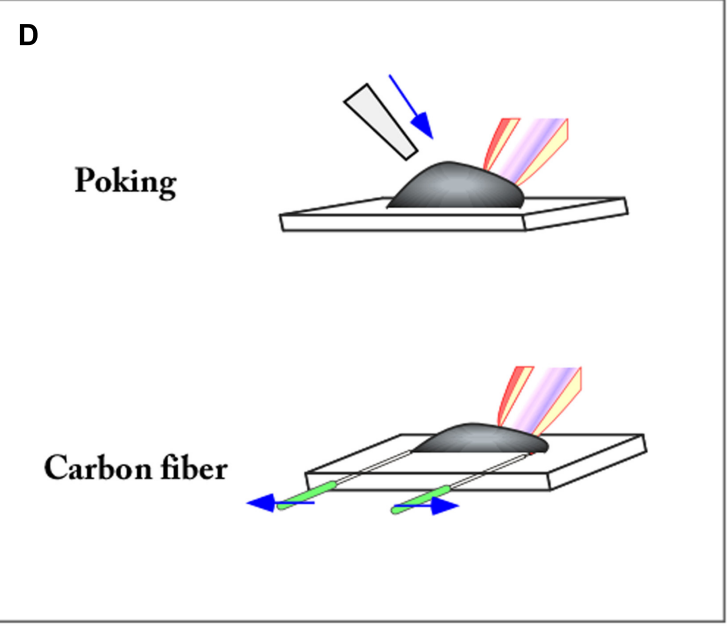

channel is elicited by pulses of increasing pressure. The open probability (Popen)-pressure relationship of the channel fit a Boltzmann function on which are mentioned: the activation threshold, the half pressure activation $\left(P_{1 / 2}\right)$, the pressure of maximum activation. (C) MS channel reconstituted in a spherical proteoliposome. (D) Poking and carbon fiber techniques allow to apply membrane stretch while recording the cell (arrows show forces applied to the system). 
MS channel is reconstituted in an artificial membrane bilayer of a spherical shaped proteoliposome (Figure 2C). Here, not only is the ionic environment well controlled, but the lipid composition of the membrane is also mastered. The absence of cytoskeleton elements is also a strong advantage allowing direct access to membrane mechanical properties without the cytoskeleton interfering with either the channel or the membrane itself. In these different configurations, applying a positive or negative pressure will allow delivery of controlled tension to the membrane if curvature of the patch is measured (Suchyna et al., 2004). Following this, single MS channels can be characterized with a very good time resolution (milliseconds) either in native or artificial membranes.

Careful and detailed analysis of physical phenomena that are generated on the patch of membrane sealed at the pipette tip have led authors to underline the limit of the patch-pressure clamp technique. Although the pressure in the pipette can be controlled precisely, its conversion into local tension, the parameter that activates MS channels, is not straightforward. In his paper, Sachs (2010) discusses the different components involved in the generation of local mechanical stress: far-field tension, phase separation, the cytoskeleton, and the adhesion energy between the membrane and the patch pipette. The pressure-clamp technique is currently one of the easiest ways to mechanically activate and record single channels, but various methods of mechanical stimulation have been developed to stimulate and record channels at the whole cell level.

\section{OTHER TECHNIOUES TO ACTIVATE MS CHANNELS}

The advantages and limitations of these techniques are a matter of active discussion (Kamkin and Kiseleva, 2008). In Figure 2D two of these techniques are illustrated. The poking technique is commonly used to apply mechanical stimulation to single cells. While recording in whole cell configuration, the stimulation is generally achieved using a fire-polished glass pipette (tip diameter 3-5 $\mu \mathrm{m}$ ). Controlled downward movements of this probe press the cell against its support, thus activating MS channels. This technique notably led to the discovery of Piezo channels (Coste et al., 2010).

The carbon fiber technique allows a controlled axial stretch of the cell and was first developed on cardiomyocytes (Le Guennec et al., 1990). Carbon fibers are attached to the cell membrane via electrostatic forces (the same forces that seal the patch-clamp pipette to the membrane). Carbon fiber bending is converted into forces generated by the cell (such as in response to an osmotic shock) while a microelectrode records the current flowing through MS channels (Figure 2D). Instead of using carbon fiber, it is also possible to use glass capillaries coated with glue. These capillaries are attached to a force transducer allowing a direct recording of the force generated by the cell while stretching. These techniques are also used to test mechanical properties of tissues such as stiffness. Regarding the poking technique, the amplitude of the downward movement compared to the cell diameter might, in some experiments, produce excessive deformation. This prompts a use of this technique with stimuli generating cell strain physiologically relevant. Until now these techniques have exclusively been developed on animal cells. Their adaptation to plant cells is of major interest in order to develop our knowledge of plant MS channels.

Both in-plane membrane tension and membrane curvature have been shown to activate MS channels. This can be achieved by asymmetric incorporation of cone-shaped amphipaths (Martinac et al., 1990). These molecules, able to insert selectively in one membrane leaflet (Sheetz and Singer, 1974), create positive or negative curvature. The activation by amphipaths differs from in-plane membrane tension because it implies local membrane curvature as the activation factor (Table 1; Yoo and Cui, 2009). MscL and MscS are activated, even in the absence of applied pressure, when cone-shaped lysophosphatidylcholine is inserted into the membrane (Vasquez et al., 2008; Mukherjee et al., 2014). This activation property is also shared by the eukaryotic channel. TREK-1 for example, is opened by crenators, while it is closed by cup-formers. (Patel et al., 1998; Maingret et al., 2000).

\section{MS CHANNELS ARE FAST TRANSDUCERS OF MEMBRANE TENSION CHANGES}

The ability to precisely control mechanical stimulation with the fast pressure clamp system has provided valuable kinetics information on the activation, inactivation, and deactivation of MS channels from different organisms. The MscS, acting as a tensiondriven osmolyte release valve in bacteria, exhibits rapid activation in the $10 \mathrm{~ms}$ time range (Boer et al., 2011). In response to sustained and moderate stimulus EcMscS exhibits complex desensitization kinetics that is composite of both channel adaptation that is likely linked to membrane mechanics and inactivation of the channel (Belyy etal., 2010; Boer et al., 2011; Kamaraju et al., 2011; Cox etal., 2014). In Figure 3A, the current decay of the MscS population is represented in the case of a sub-saturating tension applied to the membrane. In such conditions, the fraction of decrease due to inactivation is dominant over the fraction due to adaptation. However, using a specific pressure protocol (not presented in Figure 3), combining prolonged conditioning steps interspersed with short saturating pulses (Akitake et al., 2007; Kamaraju et al., 2011) allowed for distinction between these two interrelated processes and led Rowe et al. to show that inactivation is increased in the presence of crowding agents (Rowe et al., 2014). The potential physiological relevance proposed as a result of this channel adaptation and this inactivation crowded dependent is to link sensitivity to both membrane tension and crowding pressure in order to limit the dissipation of the vital gradient and to maintain cell strength and turgor during hypoosmotic shock.

Several eukaryotic MS channels also exhibit complex kinetics, with TREK and Piezo being well-known examples. They both activate in a very short period of time, in the range of a few milliseconds, and then inactivate under sustained membrane tension (Figure 3B). TREK desensitization was reported as weakly or not at all dependent on the cytoskeleton and the voltage in mammalian cells (Honore et al., 2006) and this was recently confirmed in artificial lipid bilayers where TREK and TRAAK were still inactivated (Brohawn et al., 2014). Piezol inactivation is abolished when $\mathrm{Zn}^{2+}$ instead of $\mathrm{Mg}^{2+}$ is perfused on the intracellular face and no other regulators have been described until now (Gottlieb et al., 2012). Mechanisms modulating desensitization of MS 


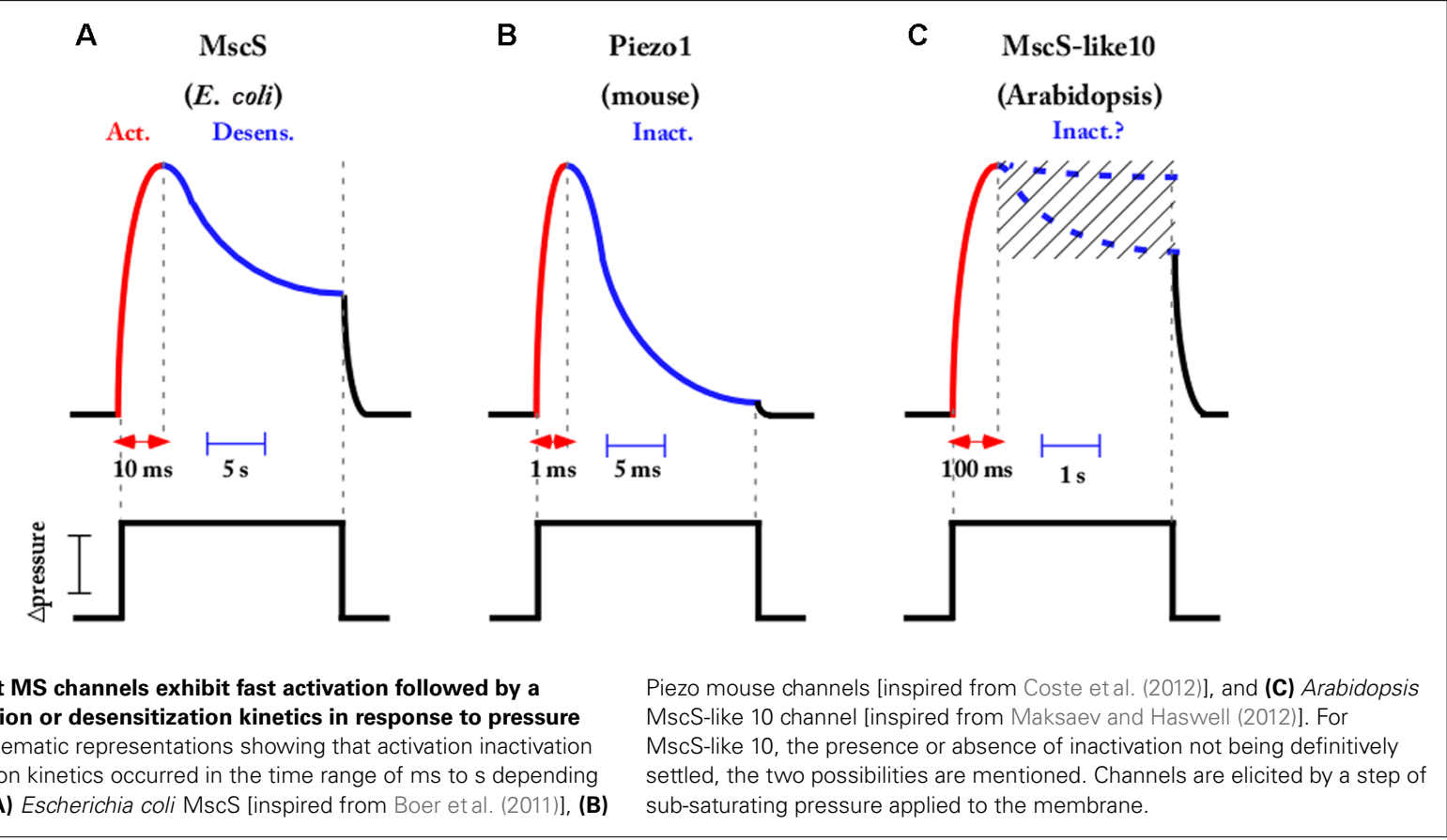

channels are far from being fully understood and deserve further study as they constitute a major characteristic of ion channel activity.

From a functional perspective, inactivation can have different roles. One role of inactivation could be to protect the cell against nonspecific responses. Indeed, inactivation guarantees that if the channel should open it cannot stay open for a long period of time. Inactivation also means that channels become desensitized to the stimulation, so if the stimulation occurs at a high frequency, the first stimulus will activate channels but not the following stimuli, and in this case the channel can act as a frequency filter.

Concerning MS channels in plants, very little electrophysiological data has been available to date. The recent discovery of anion permeable MscS-like and cation permeable MCA channels in Arabidopsis has not yet given the authors the opportunity to deliver a complete kinetics characterization. However, a recent electrophysiological study of AtMscS-like10 expressed in Xenopus oocytes (Maksaev and Haswell, 2012) indicates slow opening and closing kinetics of the channel in response to sharp steps of tension applied to the membrane. Unlike $E c \mathrm{MscS}$, but like many other prokaryotic MscS-like channels (MscSP, MscCG, MscK) (Nakayama et al., 2013; Petrov etal., 2013), no inactivation of the plant homologous under sustained tension was detected (for a review see Cox etal., 2014). The authors of the present paper also found activation and deactivation kinetics, in the $0.1 \mathrm{~s}$ range, when overexpressing AtMscS-like10 in a homologous system (Figure 3C). The existence or not of an inactivation process of the plant MscSlike10 channel is still under investigation and might depend on the expression system used (Xenopus oocyte/plant protoplast). Such an inactivation process would mean accommodation of the cell under a sustained mechanical stimulation as occurred in $E$. coli for its MscS counterpart. Further exploration is needed in plants in order to obtain a complete picture of plant MS channel function.

\section{PLANT MS CHANNELS PLANT CELLS PROVIDE A PECULIAR "MECHANICAL ENVIRONMENT" FOR MS CHANNELS}

Plant and animal cells have developed their own intracellular and extracellular matrices which differ in organization and structural composition. Plant cells exhibit very stiff pecto-cellulosic walls, notably because of the presence of cellulose microfibrils which has stiffness comparable to that of steel. Conversely, animals have wall-less cells in which the mechanical properties of the membrane are heavily dependent on the cytoskeleton network. In plants, microtubules form a dense cortical network and actin creates a slight internal network while in animal cells the situation is inverted. In the latter, cell mechanics are highly relayed to an actin contractile cytoskeleton and membrane whereas in plants, the presence of a stiff extracellular matrix is designed to moderate the contribution of the cytoskeleton. In animals, there is increasing evidence of a significant role for actin as a relay in MS channel activation (Lauritzen et al., 2005; Peyronnet et al., 2012). In plants, only one study performed on MS guard cell channels (combining electrophysiology and pharmacology) indicates channel activation when actin filaments are disrupted and channel inhibition with stabilization of actin (Zhang et al., 2007). Microtubules which represent the major mechanical component of the plant cytoskeleton (Nick, 2013) have not yet been investigated for their role in MS channel activation.

Looking deeper into the structure of the plant wall-membranecytoskeleton continuum, it is worth considering the contact points connecting these compartments. For the membrane-cytoskeleton, this is exemplified by a plethora of microtubule-associated proteins identified by the recently sequenced genomes of model plants 
(Gardiner, 2013). Cytoplasmic linker associated protein (CLASP) represents one example of these recently identified anchorage proteins although the intimate mechanism still needs to be investigated (Brandizzi and Wasteneys, 2013). The abnormal root cell swelling and increased microtubule ordering of clasp-1 mutants (Ambrose etal., 2007) stresses the importance of this linkageprotein in cell shaping and suggests a role in force cortex sensing. Another indication of the link between cell wall and microtubule networks is the parallel patterning of cellulose microfibrils with microtubules (Szymanski and Cosgrove, 2009). Furthermore, live cell imaging experiments in hypocotyl provide evidence that the cortical cytoskeleton guides the movement of cellulose synthase complexes (Paredez etal., 2006; Chan et al., 2011). The physical and biophysical significances of these tight contacts in terms of stress information is well discussed by Szymanski and Cosgrove (2009) and Cosgrove and Jarvis (2012) but little investigated by the scientific community. In addition to the contribution of their structural elements, the mechanical properties of cells largely depend on osmotic pressure commonly in the range of 2,300$6,800 \mathrm{~mm} \mathrm{Hg}(0.3-0.9 \mathrm{MPa})$ in growing cells (Cosgrove, 1993) and estimated at up to $75,000-375,000 \mathrm{~mm} \mathrm{Hg}(10-50 \mathrm{MPa})$ for wall tensile stresses. To bring these values into context and help realize how peculiar the mechanical environment is in plants, we have illustrated some pressures recorded in plant cells with regard to some milestones and pressures used in electrophysiology to activate MS channels. As tension rather than pressure activates MS channels, we have also illustrated tensions even if very little data has been available in the literature until now (Figure 4).

While turgor pressure is uniform and isotropic within the cell, wall stresses are not generally uniform, but depend on cell geometry, cell wall thickness, and wall mechanical properties. In the case of a growing cell (often encountered in plants) physical properties are dynamic, with wall extensibility varying within minutes or even seconds (Wolf et al., 2012).

All the points mentioned require integration into a biophysical vision of the plant cell. Combining molecular physics and modeling approaches will lead to drawing a map of forces within the cell, allowing crucial questions to be answered such as; what is the mechanical contribution of the cell wall? Does it absorb most of the tension applied to the cell or does the plasma membrane beneath behave as the element under tension? Are the linkage points hot spots for stress? Then, MS channels characterized by the patch clamp technique (in simplified environments: bilayer, proteoliposome, protoplast) could be mapped with the cellular strain distribution in order to understand where and when they are physiologically relevant.

\section{PROBING MECHANICAL FORCES IN PLANT. A GREAT JOB TO DO IN THE NEAR FUTURE!}

A crucial step in understanding the role of mechanosensors is to know where and when mechanical forces occur within cells and tissues and to be able to quantify them. Membrane curvature as well as membrane and cytoskeleton tension, which are essential MS channel modulators, have been poorly described until now. The main reason is that until recently, there were no techniques to study these forces in vivo. Fortunately, today this important area controlling many biological processes is regaining a lot of interest due to the emergence of new tools.

It has become better and better established that the cytoskeleton is a powerful regulator of membrane tension, shape and organization in animal cells (Ofer et al., 2011; Saravanan et al., 2013; Al-Rekabi et al., 2014). In plant cells, for which its role is less established, probing its mechanical state will be very helpful to better understand its effect on MS channels. Fluorescent probes based on the Förster resonance energy transfer (FRET) technique were recently engineered to sense tension variations within the cytoskeleton (Meng and Sachs, 2011; Guo et al., 2013) with single piconewton sensitivity (Grashoff et al., 2010). Adaptation of these sensors to plant cells represents an exciting challenge and will allow mechanical forces within the plant body to be mapped.

To complete this "strain mapping" in planta, the use of fluorescent probes sensitive to curvature (asymmetry in lipid packing) will enable the drawing of the membrane micro curvature map, another important MS channel regulator. Genetically encoded fluorescent probes already exist in animals like the BAR domain proteins (Bin1-Amphiphysin-Rvs167; Peter et al., 2004; Ren et al., 2006) which have homolog in plants (Zhuang and Jiang, 2014) and $\alpha$-Synuclein (Pranke et al., 2011). Interestingly, these curvature sensors have been shown to be efficient in different organisms (Pranke et al., 2011), making the translation to plants realistic.

Promising probes for sensing changes in the membrane mechanical state are MS channels themselves. Very recently, Wang et al. (Wang et al., 2014) revealed MscL's conformational changes using single molecule FRET. Using engineered MS channels with a FRET sensor and a known activation threshold allowed direct probing of mechanical changes. Other techniques with nongenetic probes are also being developed. For example, based on oil droplet deformations, Campás et al. (2014) describe mechanical forces within living embryonic tissues. Deformable microchips also exist to monitor tissue deformations (Kim et al., 2012). Bioimaging approaches combining the use of such tension/curvature probes with the subcellular localization of pre-labeled (with fluorescent protein) MS channels will allow the correlation of tension distribution with the presence of the channel. Such probes would help further understanding of whether MS channels are preferentially localized in the area of a curved membrane, close to cytoskeleton structures, or areas of membrane under tension, leading to the elucidation of the regulation and the role of MS channels in vivo.

\section{GENETIC APPROACH}

Several genetic strategies exist to highlight the roles of MS channels at the whole organism level. KO mutants have been extensively used to reveal MS channel functions. Bacterial Msc S and L channels (Levina et al., 1999), mammalian TREK-1 (Alloui et al., 2006; Heurteaux et al., 2006), and Piezos (Kim et al., 2012; Woo et al., 2014) are some successful examples illustrating this strategy. For plant MS channels the KO mutant approach is only in its infancy. Referring to TREK and TRAAK MS channels candidates mentioned in the first section of this review, no homologs of these 


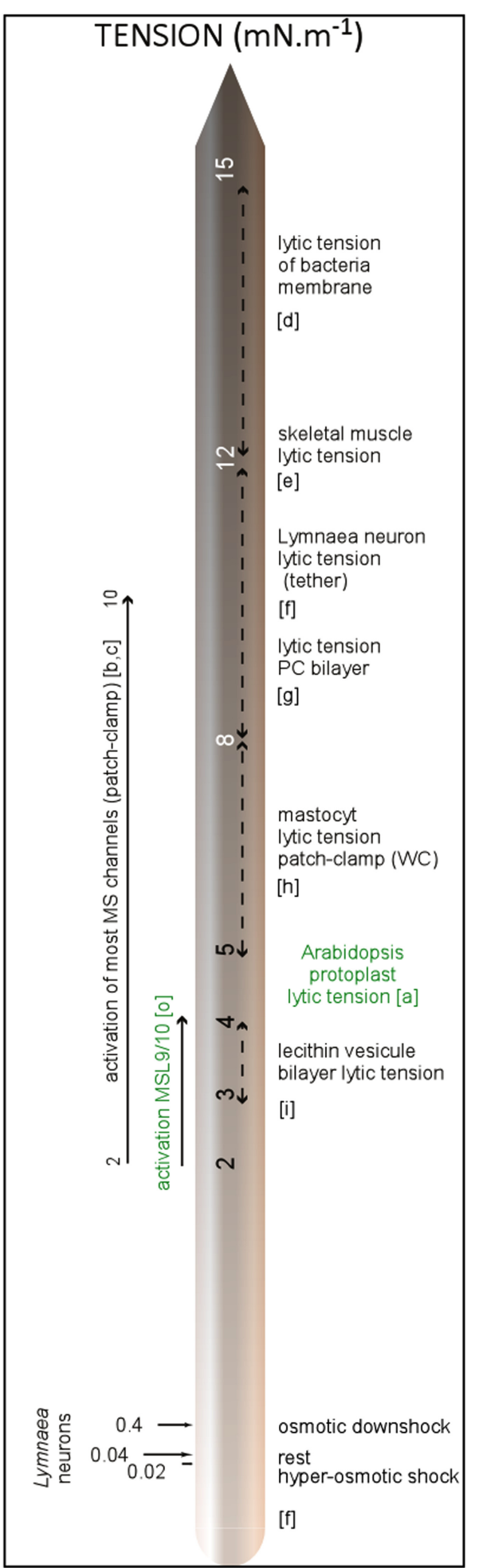

FIGURE 4 | Membrane tension and pressure within cells: milestones and experimental data. References; a: Wolfe etal. (1985), b: Gustin etal. (1988), c: Sachs and Morris (1998), d: Boer etal. (2011), e: Nichol and Hutter (1996), f: Dai etal. (1998), g: Evans and Ludwig (2000), h: Solsona etal. (1998), i: Kwok and Evans (1981), j: Meckel etal. (2004), k: Cosgrove

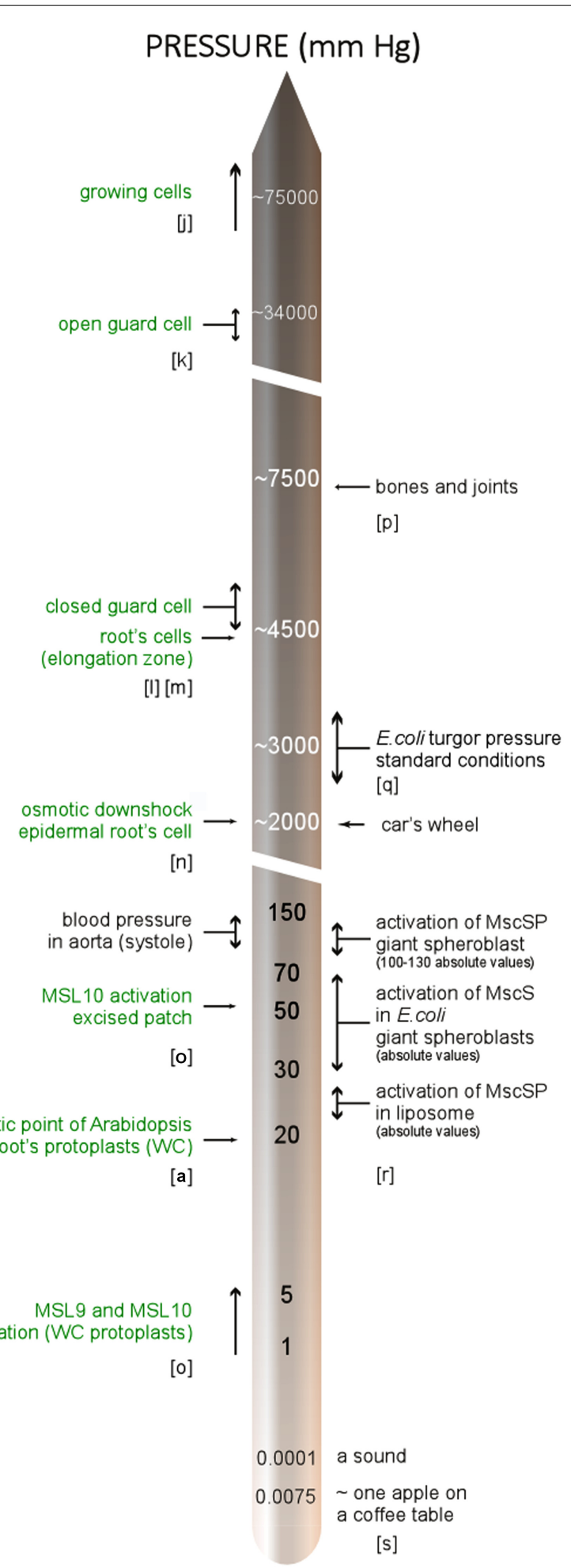

(1996), I: Franks etal. (2001), m: Pritchard etal. (1990), n: Shabala and Lew (2002), o: Haswell etal. (2008), p: Sukharev and Sachs (2012), q: (Wood, 1999), r: Petrov etal. (2013), s: Morris and Homann (2001). In green: characteristics related to plant, WC, whole-cell configuration; PC, phosphatidylcholine. 
mammalian proteins were found in currently sequenced plant genomes. By contrast, Piezo, an evolutionarily conserved protein, is expressed in invertebrates, plants, and protozoa. In plants, Piezo has only one homolog making this putative plant mechanosensor even more interesting, which urges experimenters to apply the KO strategy for this gene. In the same way, considering the prokaryotic MscS channels, homolog are present in plants but not in mammals. AtMSL 2 and 3, the closest Arabidopsis member of E. coli, were shown by Haswell and Meyerowitz (2006) and Wilson et al. (2011) to be involved in chloroplast shaping and Zring elaboration. Although AtMSL9 and AtMSL10 were proved to be channels activated by membrane stretching in Arabidopsis (Haswell et al., 2008; Peyronnet et al., 2008; Maksaev and Haswell, 2012) the KO strategy applied to these genes and related AtMSL4, AtMSL5, AtMSL6 members did not reveal phenotypes. A complementary approach to develop in this situation is the generation of gain of function (GOF) mutants. Indeed, MS channels must be closed in resting conditions in order to avoid unsuitable elicitation and unnecessary ion gradient dissipation. Hence, finding the "window of activation" is mandatory in order to obtain a phenotype. The use of conditional GOF, either in channels constitutively open or with a lowered activation threshold, can considerably enlarge this window and help reveal functions. This strategy was applied notably for Piezo2 and might be insightful for MSL in plants.

\section{COUPLING CHANNEL ACTIVATION TO SECONDARY MESSENGERS?}

The immediacy of the MS channel activation and the earliness of cellular ion fluxes and ROS variations (Monshausen et al., 2009; Coutand, 2010) in response to membrane stretching raises the question of the nature of the coupling between the channel and secondary messengers. Two types of situations might be considered. First, the simplest is due to the high capacity of the MS channel to efflux ions. As a consequence, an activation of the channel will lead to a loss of osmolyte occurring in a few minutes. This situation will lead to rapid protection of the cell against damage from hypoosmotic shock, as it does in E. coli upon activation of MscS and MscL channels. In the latter case, no immediate coupling with a second messenger is required since the predominant effect is a massive efflux of ions passively moving down the electrochemical gradient. Secondly, in less severe situations, the way in which the coupling occurs between MS channel activation and early $\mathrm{Ca}, \mathrm{pH}$, and ROS variation is still unknown. In response to either mechanical curvature of the plant root (Monshausen and Gilroy, 2009) or the oscillatory cell wall deformation occurring during hypocotyl cell elongation (Wolf et al., 2012), the earliest response is a rise in cytosolic calcium. In their attempt to connect plasma membrane stretching with $\mathrm{Ca}^{2+}$ influx, authors almost always, speculate about the intervention of a MS Ca channel. Until now, the only proposed MS channel suspected to be Ca permeable has been MCA1, which generates cation currents upon membrane stretching when expressed in Xenopus oocytes (Furuichi et al., 2012). Then, calcium influx would be amplified by a Ca-induced Ca-released mechanism requiring intracellular calcium stores. Another way to effectively link MS channels with Ca variation would be through an electrical coupling. Indeed, voltage dependent channels selective for calcium have been described on the plasma membrane (Miedema et al., 2008). These channels are activated by plasma membrane depolarization. Now, let us consider a membrane in which a MS AtMSL10 channel and a calcium voltage dependent channel coexist. Stretching this membrane will activate the AtMSL10 anion permeable channel (Haswell et al., 2008; Maksaev and Haswell, 2012) which will bring the membrane potential toward an equilibrium potential for anions $\left(\mathrm{Cl}^{-}\right.$ and $\mathrm{NO}_{3}{ }^{-}$), meaning a large depolarization. In turn, a Ca voltage dependent channel will be activated by electrocoupling (Action Potential is an example of electrocoupling between $\mathrm{Na}^{+}$and $\mathrm{K}^{+}$channels in animals) producing an inward Ca current. In order to check this scenario it is of major interest to compare, in the near future, the Ca signature of mechanically stimulated wild type versus KO plants for MS genes such as MSL, MCA, or Piezo.

\section{THE PECULIAR STATUS OF TONOPLAST MS CHANNELS}

Over the past 20 years, distinct MS channel activities have been characterized using the patch clamp method (for review see Haswell, 2007). The majority of them were described on the plasma membrane which was easily amenable to the patch clamp technique. The few studies performed on mechanogated channels on plant tonoplast did not allow for molecular identification. However, it is in 2003, in yeast (Zhou et al., 2003), that the first vacuolar membrane MS channel belonging to the TRP family was characterized. Channels of the TRP superfamily are associated with sensations of force, temperature, and chemicals in animals. These channels are formed of tetramer subunits selective for small cations. To date, no homologous has been found in plant (Kung et al., 2010; Eijkelkamp et al., 2013). The yeast TRP1, like other TRP, is polymodal, responding to voltage, membrane stretch force, and cytosolic $\mathrm{Ca}^{2+}$ concentration. In plant, only three studies (Alexandre and Lassalles, 1991; Badot et al., 1992; Maathuis, 2011) report the presence of mechanogated channels in the tonoplast membrane. The most meticulous characterization concerns a beetroot (Beta vulgaris) MS non-selective channel activated by hydrostatic and osmotic pressure but inhibited by the MS channel blocker gadolinium (Alexandre and Lassalles, 1991). It was recently shown by Maathuis (2011) that vacuolar channels from the two pores $\mathrm{K}^{+}$family (TPKs) from the three species Arabidopsis, rice, and barley were stretch sensitive. The dependence of these channels on membrane stretching and osmotic gradients led the author to propose a role for intracellular osmosensors for TPKs contributing to $\mathrm{K}^{+}$-released induced by hypo-osmotic shock. Considering the large size of the vacuole (the largest cell compartment being up to $90 \%$ of the cell volume) and the presence of MS activities in its membrane, it remains crucial to further study tonoplast mechanosensitivity. It is noteworthy that the physical forces applied to this membrane and its links with the cytoskeleton should be rather distinct to those of the plasma membrane. In conclusion, the molecular identification of tonoplast MS channels and the understanding of the role of the vacuole in mechanoperception are part of the next exciting challenges.

\section{OUTLOOK}

Despite many structural and mechanical differences, MS channels were conserved in plant and animal cells with similar 
characteristics. Considering the great difference in their life style, animal channels are presumably devoted to different functions to those of their plant counterparts. Therefore, it is of interest to predict in which function plant MS channels might be involved in order to design experimental conditions to reveal their role. If the ancestral role of the bacterial MscS channel is conserved, some MS channels might be involved in osmoregulation. Thus, looking at the kinetics of either cell swelling (root hair cell) or root ionic flux under different osmotic conditions will give an indication of this function. The root network also has to face obstacles and adapt to the hardness of the substrate during its anchorage role. Considering that MSLs are well expressed in root tissues (Haswell et al., 2008; Peyronnet et al., 2008), it is of interest to develop experimental devices in order to thoroughly study the root growth in relation to MS channel activity. Movement, although less spectacular than in animals, is ubiquitous in plants. It might be rapid, such as the closure of the Venus fly trap or leaflets of Mimosa pudica, or slow as occurs in flowers and leaves during nastic movements. All plants are also able to sense both gravity and their own shape in order to grow straight. In animals this property is called proprioception (Bastien et al., 2013). All of these reorientation movements involve osmotic pressure as well as cell curvature and are likely to require MS channels. Designing screens based on imaging to capture movement would help in deciphering the MS channel role in plants.

\section{ACKNOWLEDGMENTS}

This work is supported by the grant ANR-09-BLAN-0245-03 from the Agence Nationale de la Recherche (ANR, project SENZO) and the grant ANR-11-BSV7-010-02 from the Agence Nationale de la Recherche (ANR, project CAROLS). We apologize to all authors whose work could not be cited due to space constraints.

\section{REFERENCES}

Akitake, B., Anishkin, A., Liu, N., and Sukharev, S. (2007). Straightening and sequential buckling of the pore-lining helices define the gating cycle of MscS. Nat. Struct. Mol. Biol. 14, 1141-1149. doi: 10.1038/nsmb1341

Alexandre, J., and Lassalles, J. P. (1991). Hydrostatic and osmotic pressure activated channel in plant vacuole. Biophys. J. 60, 1326-1336. doi: 10.1016/S00063495(91)82170-1

Al-Rekabi, Z., Haase, K., and Pelling, A. E. (2014). Microtubules mediate changes in membrane cortical elasticity during contractile activation. Exp. Cell Res. 322, 21-29. doi: 10.1016/j.yexcr.2013.12.027

Alloui, A., Zimmermann, K., Mamet, J., Duprat, F., Noel, J., Chemin, J., et al. (2006). TREK-1, a $\mathrm{K}^{+}$channel involved in polymodal pain perception. EMBO J. 25, 2368-2376. doi: 10.1038/sj.emboj.7601116

Ambrose, J. C., Shoji, T., Kotzer, A. M., Pighin, J. A., and Wasteneys, G. O. (2007). The Arabidopsis CLASP gene encodes a microtubule-associated protein involved in cell expansion and division. Plant Cell 19, 2763-2775. doi: 10.1105/tpc.107.053777

Arnadottir, J., and Chalfie, M. (2010). Eukaryotic mechanosensitive channels. Annu. Rev. Biophys. 39, 111-137. doi: 10.1146/annurev.biophys.37.032807.125836

Badot, P. M., Ding, J. P., and Pickard, B. G. (1992). Mechanically activated ion channels occur in vacuoles of onion bulb scale parenchyma. C. R. Acad. Sci. Gen. $315,437-443$.

Bae, C., Gottlieb, P. A., and Sachs, F. (2013). Human PIEZO1: removing inactivation. Biophys. J. 105, 880-886. doi: 10.1016/j.bpj.2013.07.019

Bae, C., Sachs, F., and Gottlieb, P. A. (2011). The mechanosensitive ion channel piezol is inhibited by the peptide GsMTx4. Biochemistry 50, 6295-6300. doi: 10.1021/bi200770q

Bang, H., Kim, Y., and Kim, D. (2000). TREK-2, a new member of the mechanosensitive tandem-pore K1 channel family. J. Biol. Chem. 275, 17412-17419. doi: 10.1074/jbc.M000445200
Bass, R. B., Strop, P., Barclay, M., and Rees, D. C. (2002). Crystal structure of Escherichia coli MscS, a voltage-modulated and mechanosensitive channel. Science 298, 1582-1587. doi: 10.1126/science. 1077945

Bastien, R., Bohr, T., Moulia, B., and Douady, S. (2013). Unifying model of shoot gravitropism reveals proprioception as a central feature of posture control in plants. Proc. Natl. Acad. Sci. U.S.A. 110, 755-760. doi: 10.1073/pnas.12143 01109

Belyy, V., Kamaraju, K., Akitake, B., Anishkin, A., and Sukharev, S. (2010). Adaptive behavior of bacterial mechanosensitive channels is coupled to membrane mechanics. J. Gen. Physiol. 135, 641-652. doi: 10.1085/jgp.200910371

Boer, M., Anishkin, A., and Sukharev, S. (2011). Adaptive MscS gating in the osmotic permeability response in E. coli: the question of time. Biochemistry 50, 4087-4096. doi: 10.1021/bi1019435

Brandizzi, F., and Wasteneys, G. O. (2013). Cytoskeleton-dependent endomembrane organization in plant cells: an emerging role for microtubules. Plant J. 75, 339349. doi: $10.1111 /$ tpj. 12227

Brohawn, S. G., Campbell, E. B., and Mackinnon, R. (2013). Domain-swapped chain connectivity and gated membrane access in a Fab-mediated crystal of the human TRAAK K ${ }^{+}$channel. Proc. Natl. Acad. Sci. U.S.A. 110, 2129-2134. doi: 10.1073/pnas.1218950110

Brohawn, S. G., Del Marmol, J., and Mackinnon, R. (2012). Crystal structure of the human $\mathrm{K}_{2 \mathrm{P}}$ TRAAK, a lipid- and mechano-sensitive $\mathrm{K}^{+}$ion channel. Science 335, 436-441. doi: 10.1126/science. 1213808

Brohawn, S. G., Su, Z., and Mackinnon, R. (2014). Mechanosensitivity is mediated directly by the lipid membrane in TRAAK and TREK1 $\mathrm{K}^{+}$channels. Proc. Natl. Acad. Sci. U.S.A. 111, 3614-3619. doi: 10.1073/pnas.1320768111

Campás, O., Mammoto, T., Hasso, S., Sperling, R. A., O’connell, D., Bischof, A. G., et al. (2014). Quantifying cell-generated mechanical forces within living embryonic tissues. Nat. Methods 11, 183-189. doi: 10.1038/nmeth.2761

Chan, J., Eder, M., Crowell, E. F., Hampson, J., Calder, G., and Lloyd, C. (2011). Microtubules and CESA tracks at the inner epidermal wall align independently of those on the outer wall of light-grown Arabidopsis hypocotyls. J. Cell Sci. 124, 1088-1094. doi: 10.1242/jcs.086702

Chang, G., Spencer, R. H., Lee, A. T., Barclay, M. T., and Rees, D. C. (1998). Structure of the MscL homolog from Mycobacterium tuberculosis: a gated mechanosensitive ion channel. Science 282, 2220-2226. doi: 10.1126/science.282.5397.2220

Cosgrove, D. J. (1993). Water uptake by growing cells: an assessment of the controlling roles of wall relaxation, solute uptake, and hydraulic conductance. Int. J. Plant Sci. 154, 10-21. doi: 10.1086/297087

Cosgrove, D. J. (1996). Plant cell enlargement and the action of expansins. Bioessays 18, 533-540. doi: 10.1002/bies.950180704

Cosgrove, D. J., and Jarvis, M. C. (2012). Comparative structure and biomechanics of plant primary and secondary cell walls. Front. Plant Sci. 3:204. doi: 10.3389/fpls.2012.00204

Coste, B., Mathur, J., Schmidt, M., Earley, T. J., Ranade, S., Petrus, M. J., et al. (2010). Piezo1 and Piezo2 are essential components of distinct mechanically activated cation channels. Science 330, 55-60. doi: 10.1126/science.1193270

Coste, B., Xiao, B., Santos, J. S., Syeda, R., Grandl, J., Spencer, K. S., et al. (2012). Piezo proteins are pore-forming subunits of mechanically activated channels. Nature 483, 176-181. doi: 10.1038/nature10812

Coutand, C. (2010). Mechanosensing and thigmomorphogenesis, a physiological and biomechanical point of view. Plant Sci. 179, 168-182. doi: 10.1016/j.plantsci.2010.05.001

Cox, C. D., Nakayama, Y., Nomura, T., and Martinac, B. (2014). The evolutionary 'tinkering' of MscS-like channels: generation of structural and functional diversity. Pflugers Arch. doi: 10.1007/s00424-014-1522-2

Dai, J., Sheetz, M. P., Wan, X., and Morris, C. E. (1998). Membrane tension in swelling and shrinking molluscan neurons. J. Neurosci. 18, 6681-6692.

Dedman, A., Sharif-Naeini, R., Folgering, J. H., Duprat, F., Patel, A., and Honore, E. (2009). The mechano-gated K(2P) channel TREK-1. Eur. Biophys. J. 38, 293-303. doi: 10.1007/s00249-008-0318-8

Eijkelkamp, N., Quick, K., and Wood, J. N. (2013). Transient receptor potential channels and mechanosensation. Annu. Rev. Neurosci. 36, 519-546. doi: 10.1146/annurev-neuro-062012-170412

Ellis, R. J. (2001). Macromolecular crowding: obvious but underappreciated. Trends Biochem. Sci. 26, 597-604. doi: 10.1016/S0968-0004(01)01938-7

Evans, E., and Ludwig, F. (2000). Dynamic strengths of molecular anchoring and material cohesion in fluid biomembranes. J. Phys. Condens. Matter 12:A315. doi: 10.1088/0953-8984/12/8A/341 
Falke, L. C., Edwards, K. L., Pickard, B. G., and Misler, S. (1988). A stretch-activated anion channel in tobacco protoplasts. FEBS Lett. 237, 141-144. doi: 10.1016/00145793(88)80188-1

Franks, P. J., Buckley, T. N., Shope, J. C., and Mott, K. A. (2001). Guard cell volume and pressure measured concurrently by confocal microscopy and the cell pressure probe. Plant Physiol. 125, 1577-1584. doi: 10.1104/pp.125.4.1577

Furuichi, T., Iida, H., Sokabe, M., and Tatsumi, H. (2012). Expression of Arabidopsis MCAl enhanced mechanosensitive channel activity in the Xenopus laevis oocyte plasma membrane. Plant Signal. Behav. 7, 1022-1026. doi: 10.4161/psb.20783

Gardiner, J. (2013). The evolution and diversification of plant microtubuleassociated proteins. Plant J. 75, 219-229. doi: 10.1111/tpj.12189

Gauthier, N. C., Masters, T. A., and Sheetz, M. P. (2012). Mechanical feedback between membrane tension and dynamics. Trends Cell Biol. 22, 527-535. doi: 10.1016/j.tcb.2012.07.005

Gottlieb, P. A., Bae, C., and Sachs, F. (2012). Gating the mechanical channel Piezol. A comparison between whole-cell and patch recording. Channels 6, 282-289. doi: 10.4161/Chan.21064

Gottlieb, P. A., and Sachs, F. (2012). Piezol: properties of a cation selective mechanical channel. Channels 6, 214-219. doi: 10.4161/chan.21050

Grashoff, C., Hoffman, B. D., Brenner, M. D., Zhou, R., Parsons, M., Yang, M. T., et al. (2010). Measuring mechanical tension across vinculin reveals regulation of focal adhesion dynamics. Nature 466, 263-266. doi: 10.1038/nature09198

Guharay, F., and Sachs, F. (1984). Stretch-activated single ion channel currents in tissue-cultured embryonic chick skeletal muscle. J. Physiol. 352, 685-701.

Guo, J., Sachs, F., and Meng, F. (2013). Fluorescence-based force/tension sensors: a novel tool to visualize mechanical forces in structural proteins in live cells. Antioxid. Redox Signal. 20, 986-999. doi: 10.1089/ars.2013.5708

Gustin, M. C., Zhou, X. L., Martinac, B., and Kung, C. (1988). A mechanosensitive ion channel in the yeast plasma membrane. Science 242, 762-765. doi: $10.1126 /$ science. 2460920

Hamill, O. P., and Martinac, B. (2001). Molecular basis of mechanotransduction in living cells. Physiol. Rev. 81, 685-740.

Hamill, O. P., Marty, A., Neher, E., Sakmann, B., and Sigworth, F. J. (1981). Improved patch-clamp techniques for high-resolution current recording from cells and cell-free membrane patches. Pflugers Arch. 391, 85-100. doi: 10.1007/BF00656997

Haswell, E. S. (2007). "MscS-like proteins in plants,"in Mechanosensitive Ion Channels, Part A, ed. O. P. Hamill (San Diego, CA: Elsevier and Academic Press), 329-359. doi: 10.1016/S1063-5823(06)58013-5

Haswell, E. S., and Meyerowitz, E. M. (2006). MscS-like proteins control plastid size and shape in Arabidopsis thaliana. Curr. Biol. 16, 1-11. doi: 10.1016/j.cub.2005.11.044

Haswell, E. S., Peyronnet, R., Barbier-Brygoo, H., Meyerowitz, E. M., and Frachisse, J. M. (2008). Two MscS homologs provide mechanosensitive channel activities in the Arabidopsis root. Curr. Biol. 18, 730-734. doi: 10.1016/j.cub.2008. 04.039

Hayakawa, K., Tatsumi, H., and Sokabe, M. (2012). Mechano-sensing by actin filaments and focal adhesion proteins. Commun. Integr. Biol. 5, 572-577. doi: $10.4161 /$ cib. 21891

Heurteaux, C., Guy, N., Laigle, C., Blondeau, N., Duprat, F., Mazzuca, M., et al. (2004). TREK-1, a $\mathrm{K}^{+}$channel involved in neuroprotection and general anesthesia. EMBO J. 23, 2684-2695. doi: 10.1038/sj.emboj.7600234

Heurteaux, C., Lucas, G., Guy, N., El Yacoubi, M., Thummler, S., Peng, X. D., etal. (2006). Deletion of the background potassium channel TREK-1 results in a depression-resistant phenotype. Nat. Neurosci. 9, 1134-1141. doi: 10.1038/nn1749

Honore, E., Patel, A. J., Chemin, J., Suchyna, T., and Sachs, F. (2006). Desensitization of mechano-gated K2P channels. Proc. Natl. Acad. Sci. U.S.A. 103, 6859-6864. doi: 10.1073/pnas.0600463103

Hurwitz, C. G., and Segal, A. S. (2001). Application of pressure steps to mechanosensitive channels in membrane patches: a simple, economical, and fast system. Pflugers Arch. 442, 150-156. doi: 10.1007/s004240100541

Jaqaman, K., and Grinstein, S. (2012). Regulation from within: the cytoskeleton in transmembrane signaling. Trends Cell Biol. 22, 515-526. doi: 10.1016/j.tcb.2012.07.006

Kamaraju, K., Belyy, V., Rowe, I., Anishkin, A., and Sukharev, S. (2011). The pathway and spatial scale for MscS inactivation. J. Gen. Physiol. 138, 49-57. doi: 10.1085/jgp.201110606

Kamkin, A., and Kiseleva, I. (2008). "Mechanically gated channels and mechanosensitive channels," in Mechanosensitivity in Cells and Tissues: Mechanosensitive Ion
Channels, eds A. Kamkin and I. Kiseleva, (Berlin: Springer), xiii-xviii. doi: 10.1007/978-1-4020-6426-5

Kim, S. E., Coste, B., Chadha, A., Cook, B., and Patapoutian, A. (2012). The role of Drosophila Piezo in mechanical nociception. Nature 483, 209-212. doi: 10.1038/nature10801

Knepper, C., Savory, E. A., and Day, B. (2011). Arabidopsis NDR1 is an integrin-like protein with a role in fluid loss and plasma membrane-cell wall adhesion. Plant Physiol. 156, 286-300. doi: 10.1104/pp.110.169656

Kung, C., Martinac, B., and Sukharev, S. (2010). Mechanosensitive channels in microbes. Annu. Rev. Microbiol. 64, 313-329. doi: 10.1146/annurev.micro.112408.134106

Kurusu, T., Kuchitsu, K., Nakano, M., Nakayama, Y., and Iida, H. (2013). Plant mechanosensing and $\mathrm{Ca}^{2+}$ transport. Trends Plant Sci. 18, 227-233. doi: 10.1016/j.tplants.2012.12.002

Kwok, R., and Evans, E. (1981). Thermoelasticity of large lecithin bilayer vesicles. Biophys. J. 35, 637-652. doi: 10.1016/S0006-3495(81)84817-5

Lauritzen, I., Chemin, J., Honore, E., Jodar, M., Guy, N., Lazdunski, M., et al. (2005). Cross-talk between the mechano-gated $\mathrm{K}_{2 \mathrm{P}}$ channel TREK-1 and the actin cytoskeleton. EMBO Rep. 6, 642-648. doi: 10.1038/sj.embor.7400449

Le Guennec, J. Y., Peineau, N., Argibay, J. A., Mongo, K. G., and Garnier, D. (1990). A new method of attachment of isolated mammalian ventricular myocytes for tension recording: length dependence of passive and active tension. J. Mol. Cell Cardiol. 22, 1083-1093. doi: 10.1016/0022-2828(90)90072-A

Levina, N., Totemeyer, S., Stokes, N. R., Louis, P., Jones, M. A., and Booth, I. R. (1999). Protection of Escherichia coli cells against extreme turgor by activation of MscS and MscL mechanosensitive channels: identification of genes required for MscS activity. EMBO J. 18, 1730-1737. doi: 10.1093/emboj/18.7.1730

Maathuis, F. J. (2011). Vacuolar two-pore $\mathrm{K}^{+}$channels act as vacuolar osmosensors. New Phytol. 191, 84-91. doi: 10.1111/j.1469-8137.2011.03664.x

Maingret, F., Patel, A. J., Lesage, F., Lazdunski, M., and Honore, E. (2000). Lysophospholipids open the two-pore domain mechano-gated $\mathrm{K}^{+}$channels TREK-1 and TRAAK. J. Biol. Chem. 275, 10128-10133. doi: 10.1074/jbc.275.14.10128

Maksaev, G., and Haswell, E. S. (2012). MscS-Like10 is a stretch-activated ion channel from Arabidopsis thaliana with a preference for anions. Proc. Natl. Acad. Sci. U.S.A. 109, 19015-19020. doi: 10.1073/pnas.1213931109

Martinac, B. (2011). Bacterial mechanosensitive channels as a paradigm for mechanosensory transduction. Cell Physiol. Biochem. 28, 1051-1060. doi: $10.1159 / 000335842$

Martinac, B., Adler, J., and Kung, C. (1990). Mechanosensitive ion channels of E. coli activated by amphipaths. Nature 348, 261-263. doi: 10.1038/34 $8261 \mathrm{a} 0$

Martinac, B., Buechner, M., Delcour, A. H., Adler, J., and Kung, C. (1987). Pressuresensitive ion channel in Escherichia coli. Proc. Natl. Acad. Sci. U.S.A. 84, 22972301. doi: 10.1073/pnas.84.8.2297

Martinac, B., Saimi, Y., and Kung, C. (2008). Ion channels in microbes. Physiol. Rev. 88, 1449-1490. doi: 10.1152/physrev.00005.2008

McBride, D. W. Jr., and Hamill, O. P. (1992). Pressure-clamp: a method for rapid step perturbation of mechanosensitive channels. Pflugers Arch. 421, 606-612. doi: 10.1007/BF00375058

Meckel, T., Hurst, A. C., Thiel, G., and Homann, U. (2004). Endocytosis against high turgor: intact guard cells of Vicia faba constitutively endocytose fluorescently labelled plasma membrane and GFP-tagged K-channel KAT1. Plant J. 39, 182193. doi: 10.1111/j.1365-313X.2004.02119.x

Meng, F., and Sachs, F. (2011). Visualizing dynamic cytoplasmic forces with a compliance-matched FRET sensor. J. Cell Sci. 124, 261-269. doi: $10.1242 /$ jcs.071928

Miedema, H., Demidchik, V., Very, A. A., Bothwell, J. H., Brownlee, C., and Davies, J. M. (2008). Two voltage-dependent calcium channels co-exist in the apical plasma membrane of Arabidopsis thaliana root hairs. New Phytol. 179, 378-385. doi: 10.1111/j.1469-8137.2008.02465.x

Monshausen, G. B., Bibikova, T. N., Weisenseel, M. H., and Gilroy, S. (2009). $\mathrm{Ca}^{2+}$ regulates reactive oxygen species production and $\mathrm{pH}$ during mechanosensing in Arabidopsis roots. Plant Cell 21, 2341-2356. doi: 10.1105/tpc.109.0 68395

Monshausen, G. B., and Gilroy, S. (2009). Feeling green: mechanosensing in plants. Trends Cell Biol. 19, 228-235. doi: 10.1016/j.tcb.2009.02.005

Monshausen, G. B., and Haswell, E. S. (2013). A force of nature: molecular mechanisms of mechanoperception in plants. J. Exp. Bot. 64, 4663-4680. doi: 10.1093/jxb/ert204 
Morris, C. E., and Homann, U. (2001). Cell surface area regulation and membrane tension. J. Membr. Biol. 179, 79-102. doi: 10.1007/s002320010040

Mukherjee, N., Jose, M. D., Birkner, J. P., Walko, M., Ingolfsson, H. I., Dimitrova, A., et al. (2014). The activation mode of the mechanosensitive ion channel, MscL, by lysophosphatidylcholine differs from tension-induced gating. FASEB J. 28, 4292-4302. doi: 10.1096/fj.14-251579

Nakagawa, Y., Katagiri, T., Shinozaki, K., Qi, Z., Tatsumi, H., Furuichi, T., et al. (2007). Arabidopsis plasma membrane protein crucial for $\mathrm{Ca}^{2+}$ influx and touch sensing in roots. Proc. Natl. Acad. Sci. U.S.A. 104, 3639-3644. doi: 10.1073/pnas.0607703104

Nakayama, Y., Yoshimura, K., and Iida, H. (2013). Electrophysiological characterization of the mechanosensitive channel MscCG in Corynebacterium glutamicum. Biophys. J. 105, 1366-1375. doi: 10.1016/j.bpj.2013.06.054

Nichol, J. A., and Hutter, O. F. (1996). Tensile strength and dilatational elasticity of giant sarcolemmal vesicles shed from rabbit muscle. J. Physiol. 493(Pt 1), 187-198.

Nick, P. (2013). Microtubules, signalling and abiotic stress. Plant J. 75, 309-323. doi: $10.1111 /$ tpj.12102

Nilius, B., and Honore, E. (2012). Sensing pressure with ion channels. Trends Neurosci. 35, 477-486. doi: 10.1016/j.tins.2012.04.002

Noel, J., Sandoz, G., and Lesage, F. (2011). Molecular regulations governing TREK and TRAAK channel functions. Channels 5, 402-409. doi: 10.4161/chan.5.5.16469

Nomura, T., Cranfield, C. G., Deplazes, E., Owen, D. M., Macmillan, A., Battle, A. R., et al. (2012). Differential effects of lipids and lyso-lipids on the mechanosensitivity of the mechanosensitive channels MscL and MscS. Proc. Natl. Acad. Sci. U.S.A. 109, 8770-8775. doi: 10.1073/pnas. 1200051109

Ofer, N., Mogilner, A., and Keren, K. (2011). Actin disassembly clock determines shape and speed of lamellipodial fragments. Proc. Natl. Acad. Sci. U.S.A. 108 20394-20399. doi: 10.1073/pnas.1105333108

Paredez, A. R., Somerville, C. R., and Ehrhardt, D. W. (2006). Visualization of cellulose synthase demonstrates functional association with microtubules. Science 312, 1491-1495. doi: 10.1126/science.1126551

Patel, A. J., Honore, E., Maingret, F., Lesage, F., Fink, M., Duprat, F., et al. (1998). A mammalian two pore domain mechano-gated S-like $\mathrm{K}^{+}$channel. EMBO J. 17, 4283-4290. doi: 10.1093/emboj/17.15.4283

Perozo, E., Kloda, A., Cortes, D. M., and Martinac, B. (2002). Physical principles underlying the transduction of bilayer deformation forces during mechanosensitive channel gating. Nat. Struct. Biol. 9, 696-703. doi: 10.1038/nsb827

Perozo, E., and Rees, D. C. (2003). Structure and mechanism in prokaryotic mechanosensitive channels. Curr. Opin. Struct. Biol. 13, 432-442. doi: 10.1016/S0959-440X(03)00106-4

Peter, B. J., Kent, H. M., Mills, I. G., Vallis, Y., Butler, P. J., Evans, P. R., et al. (2004). BAR domains as sensors of membrane curvature: the amphiphysin BAR structure. Science 303, 495-499. doi: 10.1126/science.1092586

Petrov, E., Palanivelu, D., Constantine, M., Rohde, P. R., Cox, C. D., Nomura T., et al. (2013). Patch-clamp characterization of the MscS-like mechanosensitive channel from Silicibacter pomeroyi. Biophys. J. 104, 1426-1434. doi: 10.1016/j.bpj.2013.01.055

Peyronnet R., Haswell, E. S., Barbier-Brygoo H., and Frachisse, J. M. (2008). AtMSL9 and AtMSL10: Sensors of plasma membrane tension in Arabidopsis roots. Plant Signal. Behav. 3, 726-729. doi: 10.4161/psb.3.9.6487

Peyronnet, R., Sharif-Naeini, R., Folgering, J. H., Arhatte, M., Jodar, M., El Boustany, C., et al. (2012). Mechanoprotection by polycystins against apoptosis is mediated through the opening of stretch-activated $\mathrm{K}_{2 \mathrm{P}}$ channels. Cell Rep. 1, 241-250. doi: 10.1016/j.celrep.2012.01.006

Pranke, I. M., Morello, V., Bigay, J., Gibson, K., Verbavatz, J. M., Antonny, B., et al. (2011). alpha-Synuclein and ALPS motifs are membrane curvature sensors whose contrasting chemistry mediates selective vesicle binding. J. Cell Biol. 194, 89-103. doi: $10.1083 /$ jcb.201011118

Pritchard, J., Barlow, P. W., Adam, J. S., and Tomos, A. D. (1990). Biophysics of the inhibition of the growth of maize roots by lowered temperature. Plant Physiol. 93, 222-230. doi: 10.1104/pp.93.1.222

Ren, G., Vajjhala, P., Lee, J. S., Winsor, B., and Munn, A. L. (2006). The BAR domain proteins: molding membranes in fission, fusion, and phagy. Microbiol. Mol. Biol. Rev. 70, 37-120. doi: 10.1128/MMBR.70.1.37-120.2006

Rowe, I., Anishkin, A., Kamaraju, K., Yoshimura, K., and Sukharev, S. (2014). The cytoplasmic cage domain of the mechanosensitive channel MscS is a sensor of macromolecular crowding. J. Gen. Physiol. 143, 543-557. doi: 10.1085/jgp.201311114
Sachs, F. (2010). Stretch-activated ion channels: what are they? Physiology (Bethesda) 25, 50-56. doi: 10.1152/physiol.00042.2009

Sachs, F., and Morris, C. E. (1998). Mechanosensitive ion channels in nonspecialized cells. Rev. Physiol. Biochem. Pharmacol. 132, 1-77. doi: 10.1007/BFb0004985

Saravanan, S., Meghana, C., and Narasimha, M. (2013). Local, cell-nonautonomous feedback regulation of myosin dynamics patterns transitions in cell behavior: a role for tension and geometry? Mol. Biol. Cell 24, 2350-2361. doi: 10.1091/mbc.E12-12-0868

Shabala, S. N., and Lew, R. R. (2002). Turgor regulation in osmotically stressed Arabidopsis epidermal root cells. Direct support for the role of inorganic ion uptake as revealed by concurrent flux and cell turgor measurements. Plant Physiol. 129, 290-299. doi: 10.1104/pp.020005

Sheetz, M. P., and Singer, S. J. (1974). Biological membranes as bilayer couples. A molecular mechanism of drug-erythrocyte interactions. Proc. Natl. Acad. Sci. U.S.A. 71, 4457-4461. doi: 10.1073/pnas.71.11.4457

Solsona, C., Innocenti, B., and Fernandez, J. M. (1998). Regulation of exocytotic fusion by cell inflation. Biophys. J. 74, 1061-1073. doi: 10.1016/S00063495(98)74030-5

Sotomayor, M., Vasquez, V., Perozo, E., and Schulten, K. (2007). Ion conduction through MscS as determined by electrophysiology and simulation. Biophys. J. 92, 886-902. doi: 10.1529/biophysj.106.095232

Suchyna, T. M., Tape, S. E., Koeppe, R. E. II, Andersen, O. S., Sachs, F., and Gottlieb, P. A. (2004). Bilayer-dependent inhibition of mechanosensitive channels by neuroactive peptide enantiomers. Nature 430, 235-240. doi: 10.1038 /nature 02743

Sukharev, S. (1999). Mechanosensitive channels in bacteria as membrane tension reporters. FASEB J. 13 (Suppl.), S55-S61.

Sukharev, S. (2002). Purification of the small mechanosensitive channel of Escherichia coli $(\mathrm{MscS})$ : the subunit structure, conduction, and gating characteristics in liposomes. Biophys. J. 83, 290-298. doi: 10.1016/S0006-3495(02) 75169-2

Sukharev, S., Betanzos, M., Chiang, C. S., and Guy, H. R. (2001). The gating mechanism of the large mechanosensitive channel MscL. Nature 409, 720-724. doi: $10.1038 / 35055559$

Sukharev, S., and Sachs, F. (2012). Molecular force transduction by ion channels: diversity and unifying principles. J. Cell Sci. 125, 3075-3083. doi: 10.1242 /jcs.092353

Sukharev, S. I., Blount, P., Martinac, B., Blattner, F. R., and Kung, C. (1994a). A large-conductance mechanosensitive channel in E. coli encoded by $\mathrm{mscL}$ alone. Nature 368, 265-268. doi: 10.1038/368265a0

Sukharev, S. I., Martinac, B., Blount, P., and Kung, C. (1994b). Functional reconstitution as an assay for biochemical isolation of channel proteins: application to the molecular identification of a bacterial mechanosensitive channel. Methods 6, 51-59. doi: 10.1006/meth.1994.1007

Sukharev, S. I., Blount, P., Martinac, B., and Kung, C. (1997). Mechanosensitive channels of Escherichia coli: the MscL gene, protein, and activities. Annu. Rev. Physiol. 59, 633-657. doi: 10.1146/annurev.physiol.59.1.633

Sukharev, S. I., Sigurdson, W. J., Kung, C., and Sachs, F. (1999). Energetic and spatial parameters for gating of the bacterial large conductance mechanosensitive channel, MscL. J. Gen. Physiol. 113, 525-540. doi: 10.1085/jgp.113.4.525

Szymanski, D. B., and Cosgrove, D. J. (2009). Dynamic coordination of cytoskeletal and cell wall systems during plant cell morphogenesis. Curr. Biol. 19, R800-R811. doi: 10.1016/j.cub.2009.07.056

Teng, J., Loukin, S., Anishkin, A., and Kung, C. (2014). The force-from-lipid (FFL) principle of mechanosensitivity, at large and in elements. Pflugers Arch. doi: 10.1007/s00424-014-1530-2 [Epub ahead of Print].

Vasquez, V., Sotomayor, M., Cordero-Morales, J., Schulten, K., and Perozo, E. (2008). A structural mechanism for MscS gating in lipid bilayers. Science 321, 1210-1214. doi: 10.1126/science.1159674

Wang, Y., Liu, Y., Deberg, H. A., Nomura, T., Hoffman, M. T., Rohde, P. R., et al. (2014). Single molecule FRET reveals pore size and opening mechanism of a mechano-sensitive ion channel. Elife 3:e01834. doi: 10.7554/eLife. 01834

Wilson, M. E., Jensen, G. S., and Haswell, E. S. (2011). Two mechanosensitive channel homologs influence division ring placement in Arabidopsis chloroplasts. Plant Cell 23, 2939-2949. doi: 10.1105/tpc.111.088112

Wilson, M. E., Maksaev, G., and Haswell, E. S. (2013). MscS-like mechanosensitive channels in plants and microbes. Biochemistry 52, 5708-5722. doi: $10.1021 / \mathrm{bi} 400804 \mathrm{z}$ 
Wolf, S., Hematy, K., and Hofte, H. (2012). Growth control and cell wall signaling in plants. Annu. Rev. Plant Biol. 63, 381-407. doi: 10.1146/annurev-arplant042811-105449

Wolfe, J., Dowgert, M. F., and Steponkus, P. L. (1985). Dynamics of membrane exchange of the plasma membrane and the lysis of isolated protoplasts during rapid expansion in area. J. Membr. Biol. 86, 127-138. doi: 10.1007/BF01 870779

Woo, S. H., Ranade, S., Weyer, A. D., Dubin, A. E., Baba, Y., Qiu, Z., et al. (2014). Piezo2 is required for Merkel-cell mechanotransduction. Nature 509, 622-626. doi: $10.1038 /$ nature 13251

Wood, J. M. (1999). Osmosensing by bacteria: signals and membrane-based sensors. Microbiol. Mol. Biol. Rev. 63, 230-262.

Yoo, J., and Cui, Q. (2009). Curvature generation and pressure profile modulation in membrane by lysolipids: insights from coarse-grained simulations. Biophys. J. 97, 2267-2276. doi: 10.1016/j.bpj.2009.07.051

Zarychanski, R., Schulz, V. P., Houston, B. L., Maksimova, Y., Houston, D. S., Smith, B., et al. (2012). Mutations in the mechanotransduction protein PIEZO1 are associated with hereditary xerocytosis. Blood 120, 1908-1915. doi: 10.1182/blood2012-04-422253

Zhang, W., Fan, L. M., and Wu, W. H. (2007). Osmo-sensitive and stretchactivated calcium-permeable channels in Vicia faba guard cells are regulated by actin dynamics. Plant Physiol. 143, 1140-1151. doi: 10.1104/pp.106. 091405
Zhou, X. L., Batiza, A. F., Loukin, S. H., Palmer, C. P., Kung, C., and Saimi, Y. (2003). The transient receptor potential channel on the yeast vacuole is mechanosensitive. Proc. Natl. Acad. Sci. U.S.A. 100, 7105-7110. doi: 10.1073/pnas. 1230540100

Zhuang, X., and Jiang, L. (2014). Autophagosome biogenesis in plants: roles of SH3P2. Autophagy 10, 704-705. doi: 10.4161/auto.28060

Conflict of Interest Statement: The authors declare that the research was conducted in the absence of any commercial or financial relationships that could be construed as a potential conflict of interest.

Received: 01 July 2014; accepted: 29 September 2014; published online: 21 October 2014

Citation: Peyronnet R, Tran D, Girault T and Frachisse J-M (2014) Mechanosensitive channels: feeling tension in a world under pressure. Front. Plant Sci. 5:558. doi: 10.3389/fpls.2014.00558

This article was submitted to Plant Physiology, a section of the journal Frontiers in Plant Science.

Copyright (C) 2014 Peyronnet, Tran, Girault and Frachisse. This is an open-access article distributed under the terms of the Creative Commons Attribution License (CC BY). The use, distribution or reproduction in other forums is permitted, provided the original author(s) or licensor are credited and that the original publication in this journal is cited, in accordance with accepted academic practice. No use, distribution or reproduction is permitted which does not comply with these terms. 